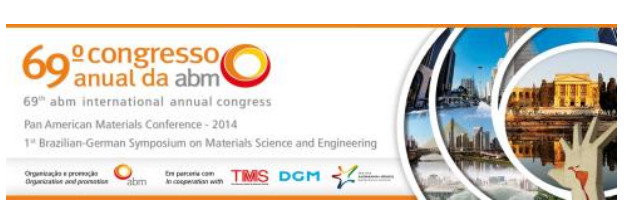

Tema: Tratamento Térmico

\title{
UTILIZAÇÃO DE UM ATAQUE POR IMERSÃO NA CARACTERIZAÇÃO DA INFLUÊNCIA DA TEMPERATURA E DO TEMPO DE AUSTENITIZAÇÃO SOBRE O TAMANHO DE GRÃO AUSTENÍTICO E MORFOLOGIA DA MARTENSITA EM UM AÇO DO TIPO ABNT 1045*
}

\author{
Priscila Graziela Melo Martins ${ }^{1}$ \\ Geraldo Lúcio de Faria² \\ Leonardo Barbosa Godefroid ${ }^{3}$ \\ Raimundo Teixeira Costa ${ }^{4}$
}

\section{Resumo}

O tamanho de grão austenítico é um parâmetro que influencia o desempenho de tratamentos térmicos em aços, assim como suas propriedades. Neste contexto, este trabalho investigou o uso de um reativo para ataque por imersão $(240 \mathrm{ml}$ de água destilada, $2 \mathrm{ml}$ de $\mathrm{HCl}, 2 \mathrm{~g}$ de ácido pícrico e 5 gotas de detergente neutro) para avaliar a influência da temperatura e do tempo de austenitização sobre o tamanho de grão austenítico de um aço ABNT1045 austenitizado nas temperaturas de $860^{\circ} \mathrm{C}, 950^{\circ} \mathrm{C}$ e $1100^{\circ} \mathrm{C}$ por intervalos de tempo de 40, 90 e 180 minutos. As amostras austenitizadas foram temperadas em água, metalograficamente preparadas e atacadas com o reativo proposto com o objetivo de se revelar os antigos contornos de grãos austeníticos. Os tamanhos de grãos foram medidos com a utilização do software UMIAS de forma a possibilitar a determinação de distribuições estatísticas com quinhentas medidas para cada condição de tratamento. As amostras foram novamente preparadas e então atacadas com Nital $2 \%$, sendo possível avaliar a influência do tamanho de grão austenítico sobre a morfologia da martensita. Pôde-se observar que, para o aço ABNT1045, a influência da temperatura de austenitização sobre o tamanho de grão austenítico é muito evidente e mais significativa do que a do tempo. Os valores de tamanho de grão se mostraram exponencialmente dependentes da temperatura, de forma que quanto maior o tamanho de grão austenítico, mais grosseira é a estrutura martensítica e menor é a dureza do material após a têmpera em água.

Palavras-chave: Ataque por imersão; Austenitização; Tamanho de Grão; Martensita.

\section{APPLICATION OF IMMERSION ETCHING AIMING TO CHARACTERIZE THE INFLUENCE OF AUSTENITIZING TEMPERATURE AND TIME ON AUSTENITE GRAIN SIZE AND MARTENSITE MORFOLOGY IN AN ABNT1045 STEEL}

\begin{abstract}
Austenite grain size is an important parameter which has a strong influence on steel heat treatments success. This work investigated the use of an immersion etching $(240 \mathrm{ml}$ of distilled water, $2 \mathrm{ml}$ of $\mathrm{HCl}, 2 \mathrm{~g}$ of picric acid and 5 drops of neutral soap) aiming to evaluate the austenitizing temperature and time on austenite grain size in a ABNT 1045 steel heated in $860^{\circ} \mathrm{C}$, $950^{\circ} \mathrm{C}$ and $1100^{\circ} \mathrm{C}$ for 40,90 and 180 minutes. Samples were austenitized and quenched in room temperature water. Quenched samples were prepared for metallographic characterization and etched with proposed solution aiming to revel austenite grain boundaries. Austenite grain sizes were measured with UMIAS software and a statistical distribution were built using five hundred measurements for each condition of heat treatment. After that, samples were one more time prepared and etched with nital $2 \%$. Using this solution, it was possible to study the austenite grain size on martensite morphology. It was possible to conclude that, for ABNT1045 steel, austenitizing temperature has a high influence on austenite grain size, which growths exponentially with temperature. The austenitizing time at a fixed temperature has a low influence on this parameter. The higher the austenite grain size, the coarser martensite and the lower hardness.

Keywords: Immersion Etching; Austenitizing; Grain size; Martensite.

\footnotetext{
Graduanda em Engenharia Metalúrgica, Universidade Federal de Ouro Preto, Ouro Preto, MG, Brasil. Físico, Dr., Professor, DEMET, Universidade Federal de Ouro Preto, Ouro Preto, MG, Brasil.

Engenheiro, Dr., Professor, DEMET, Universidade Federal de Ouro Preto, Ouro Preto, MG, Brasil.

Engenheiro, MSc., Professor, DEMET, Universidade Federal de Ouro Preto, Ouro Preto, MG, Brasil.
}

\footnotetext{
* Contribuição técnica ao 69ํ Congresso Anual da ABM - Internacional e ao 14ํㅡㄹ ENEMET - Encontro Nacional de Estudantes de Engenharia Metalúrgica, de Materiais e de Minas, 21 a 25 de julho de 2014, São Paulo, SP, Brasil.
} 


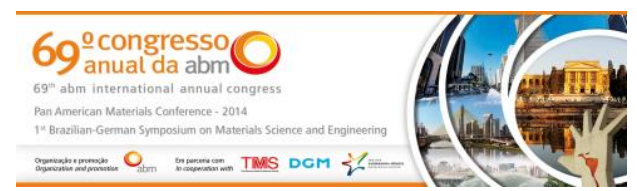

\section{INTRODUÇÃO}

O tamanho de grão austenítico tem uma grande influência sobre a microestrutura e as propriedades mecânicas, elétricas e magnéticas dos aços. Neste contexto, o desenvolvimento e a aplicação de técnicas que permitam quantificar com precisão o tamanho de grão austenítico têm importância nos estudos metalúrgicos [1-7].

Um dos desafios para se conseguir estudar precisamente as relações entre o tamanho de grão austenítico e as características do aço está na aplicação de técnicas de contraste óptico que possibilitem a observação nítida dos grãos de austenita. Uma vez revelados os grãos, seus tamanhos podem ser facilmente medidos [8-11].

Diferentes métodos para revelação do antigo contorno de grão austenítico têm sido desenvolvidos e podem ser classificados em dois grupos: o primeiro consiste em procedimentos que se baseiam na observação direta da microestrutura austenítica acima da temperatura crítica, fazendo uso de microscopia de alta temperatura [12 e 13]; o segundo usa procedimentos indiretos, nos quais técnicas metalográficas e tratamentos térmicos pós-austenitização são aplicados para revelar os contornos de grãos austeníticos à temperatura ambiente [14,15].

Sabe-se que a sensitização dos contornos de grãos podem ser estimuladas pelo aquecimento das amostras em atmosfera oxidante, e ainda que alguns reativos têm a habilidade de revelar os contornos de grãos austeníticos quando eles contém segregação de alguns elementos químicos, como por exemplo fósforo. Diversas técnicas tentam explorar a sensitização como potencial mecanismo de contraste óptico [8-15].

Andrés et al. [12] estudaram diferentes técnicas a quente com o objetivo de diagnosticar qual delas apresenta melhor desempenho no que diz respeito a revelar o antigo contorno de grão austenítico de aços médio carbono microligados. Segundo os autores, diversos métodos podem ser aplicados, entre os testados por eles o de melhor desempenho foi o ataque térmico denominado HT6. Este ataque consistiu em lixar e polir amostras do aço e em seguida as submeter a um aquecimento em um forno de radiação a vácuo até a temperatura de austenitização. Em seguida a amostra foi transferia para um forno elétrico ao ar onde permaneceu por algum tempo, sendo em seguida temperada e observada ao microscópio.

Como os procedimentos que envolvem tratamentos térmicos são muito elaborados e exigem equipamentos mais sofisticados, os ataques que fazem uso de reativos à temperatura ambiente têm sido muito estudados. Entre os mais citados, estão os reativos à base de solução aquosa de ácido pícrico com agentes que diminuem a tensão superficial da água [12,14,15].

Neste contexto este trabalho se propôs a avaliar a utilização de um reativo para ataque por imersão como ferramenta para revelar o antigo contorno de grão austenítico de amostras de aço ABNT 1045 austenitizadas em diferentes condições, assim como avaliar a influência do tempo e temperatura de austenitização sobre o tamanho de grão austenítco e sobre a morfologia da martensita formada.

\section{MATERIAIS E MÉTODOS}

\subsection{Materiais}

O material objeto deste estudo consiste no aço carbono ABNT 1045, cuja especificação química está apresentada na Tabela 1. Inicialmente, amostras

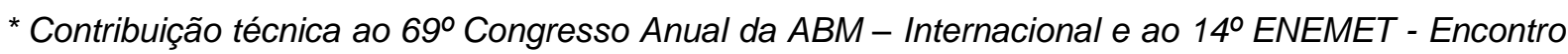
Nacional de Estudantes de Engenharia Metalúrgica, de Materiais e de Minas, 21 a 25 de julho de 2014, São Paulo, SP, Brasil. 


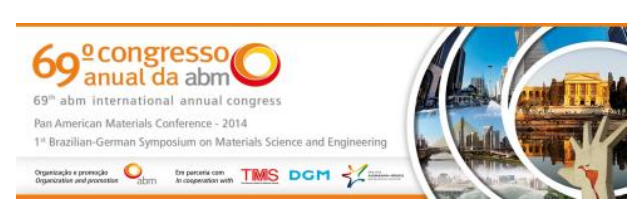

representativas foram retiradas de uma barra por meio de procedimentos de corte por abrasão refrigerados realizados em uma cortadora metalográfica (cutoff).

Uma amostra foi destinada à caracterização química, por meio da técnica de espectrometria de emissão óptica e outra para caracterização estrutural do estado de entrega por meio da aplicação de microscopia óptica de luz refletida.

Tabela 1. Especificação química do aço ABNT 1045 (\%em massa)

\begin{tabular}{ccccc}
\hline$C$ & $M n$ & $P_{\text {máx }}$ & $S_{\text {máx }}$ & Si \\
\hline $0,43-0,50$ & $0,60-0,90$ & 0,040 & 0,050 & $0,10-0,60$ \\
\hline
\end{tabular}

\subsection{Procedimentos Experimentais}

Caracterizado o estado de entrega do aço ABNT 1045, a etapa seguinte consistiu na realização de tratamentos térmicos de austenitização em nove amostras. A austenitização das amostras foi avaliada em três temperaturas, que foram: $860^{\circ} \mathrm{C}$, $950^{\circ} \mathrm{C}$ e $1100^{\circ} \mathrm{C}$. Para cada temperatura foram avaliados três intervalos de tempo distintos de austenitização: 40min, 90min e 180min. Para todas as condições de austenitização testadas, as amostras foram seguidamente temperadas em água à temperatura ambiente com agitação.

Com o objetivo de simplificar a identificação das amostras, elas foram identificadas pelas letras de A a I, como é indicado no fluxograma apresentado na Figura 1 que também resume as etapas subsequentes a austenitização e caracterização das amostras.

Para revelar o antigo contorno de grão da austenita, foi requerida a etapa de preparação metalográfica das amostras com o objetivo de remover o óxido (carepa) formado durante o tratamento térmico e preparar as superfícies das mesmas para os procedimentos de ataque químico. A análise do tamanho de grão austenítico foi realizada revelando os antigos contornos de grãos da austenita, pela técnica de ataque por imersão com o reativo constituído por $240 \mathrm{ml}$ de água destilada, $2 \mathrm{ml}$ de $\mathrm{HCl}, 2 \mathrm{~g}$ de ácido pícrico e 5 gotas de detergente neutro, durante um intervalo de tempo de $30 \pm 5$ segundos. Esse ataque foi realizado à temperatura ambiente.

Após a revelação do antigo grão austenítico, para cada uma das condições de tratamento testadas, imagens da estrutura foram adquiridas com os aumentos de 100x e 400x. Os tamanhos médios de grão austenítico foram determinados por meio de um método não normatizado com a utilização do software metalográfico quantitativo UMIAS. Esse método constitui em sobrepor aos grãos segmentos de retas perpendiculares entre si. Os pontos de interseção entre cada reta e os contornos foram identificados, e a distância entre dois pontos opostos foi determinada. A Figura 2 exemplifica a técnica descrita. Para cada amostra foram realizadas 560 medidas, distribuídas em aproximadamente 10 campos.

\footnotetext{
* Contribuição técnica ao $69^{\circ}$ Congresso Anual da ABM - Internacional e ao 14ํㅡㄹ ENEMET - Encontro Nacional de Estudantes de Engenharia Metalúrgica, de Materiais e de Minas, 21 a 25 de julho de 2014, São Paulo, SP, Brasil.
} 


\section{RESULTADOS E DISCUSSÃO}

\subsection{Caracterização Química e Estrutural}

A Figura 3 apresenta um gráfico onde são comparados os teores reais de $\mathrm{C}, \mathrm{Mn}, \mathrm{P}$, $\mathrm{S}$ e Si com os especificados pela norma ABNT NBR 87/2000. Pode-se observar que o aço estudado neste trabalho atende aos requisitos mínimos e máximos exigidos, se enquadrando assim na especificação de um aço ABNT 1045.

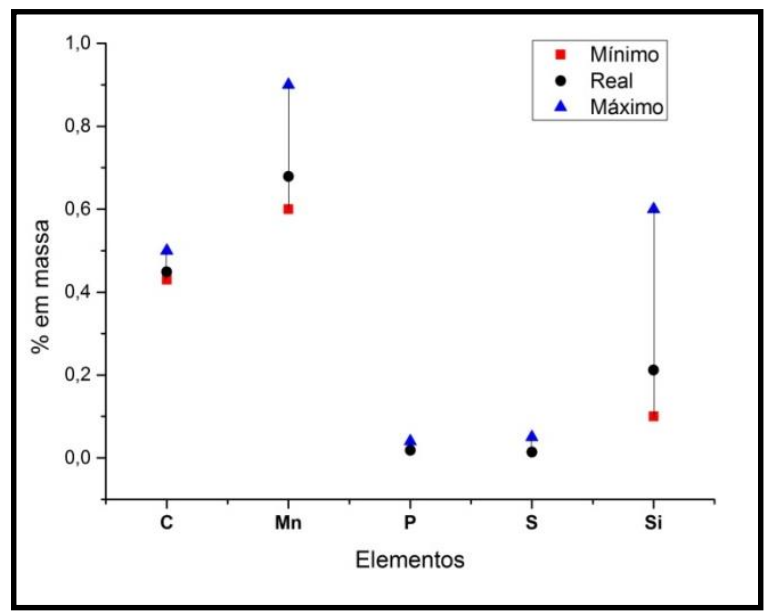

Figura 3. Comparativo entre composição e especificação química do aço ABNT 1045 estudado neste trabalho.

A Figura 4 apresenta os resultados obtidos pela aplicação da técnica de metalografia no estado de entrega da amostra estudada. A Figura 4(a) evidencia uma micrografia da amostra no estado de entrega apenas polida. Pode-se notar que se trata de um material que possui pequena fração de inclusões com morfologia esferoidal. As Figuras 4(b) e 4(c) apresentam micrografias da amostra no estado de entrega após ser submetida a ataque com Nital $2 \%$. Pode-se observar que a microestrutura é constituída por ferrita proeutetóide e perlita. Observa-se ainda que a ferrita proeutetóide nucleou-se preferencialmente nos antigos contornos de grão da austenita que mais tarde viera a se transformar em perlita. Trata-se de uma estrutura homogênea típica de um aço ABNT 1045 normalizado.

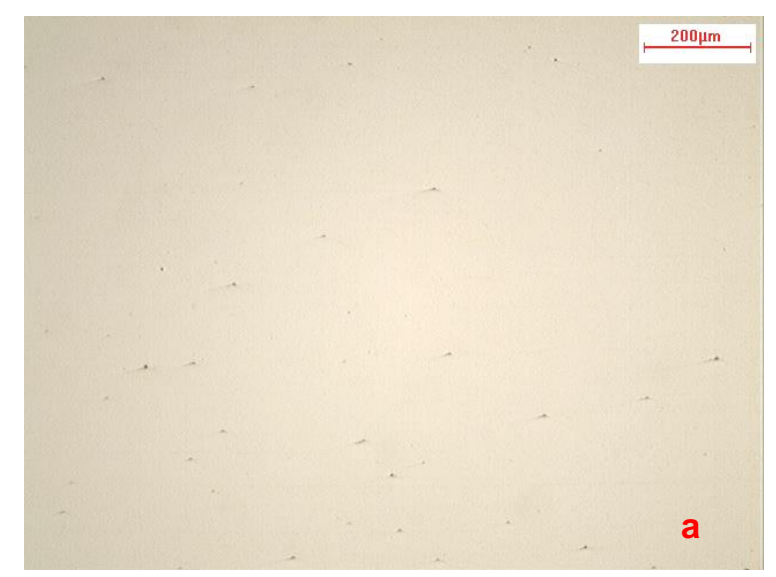

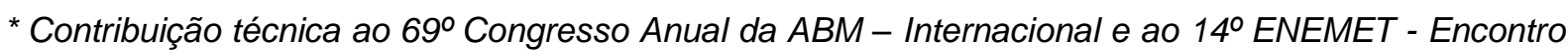
Nacional de Estudantes de Engenharia Metalúrgica, de Materiais e de Minas, 21 a 25 de julho de 2014, São Paulo, SP, Brasil.
} 

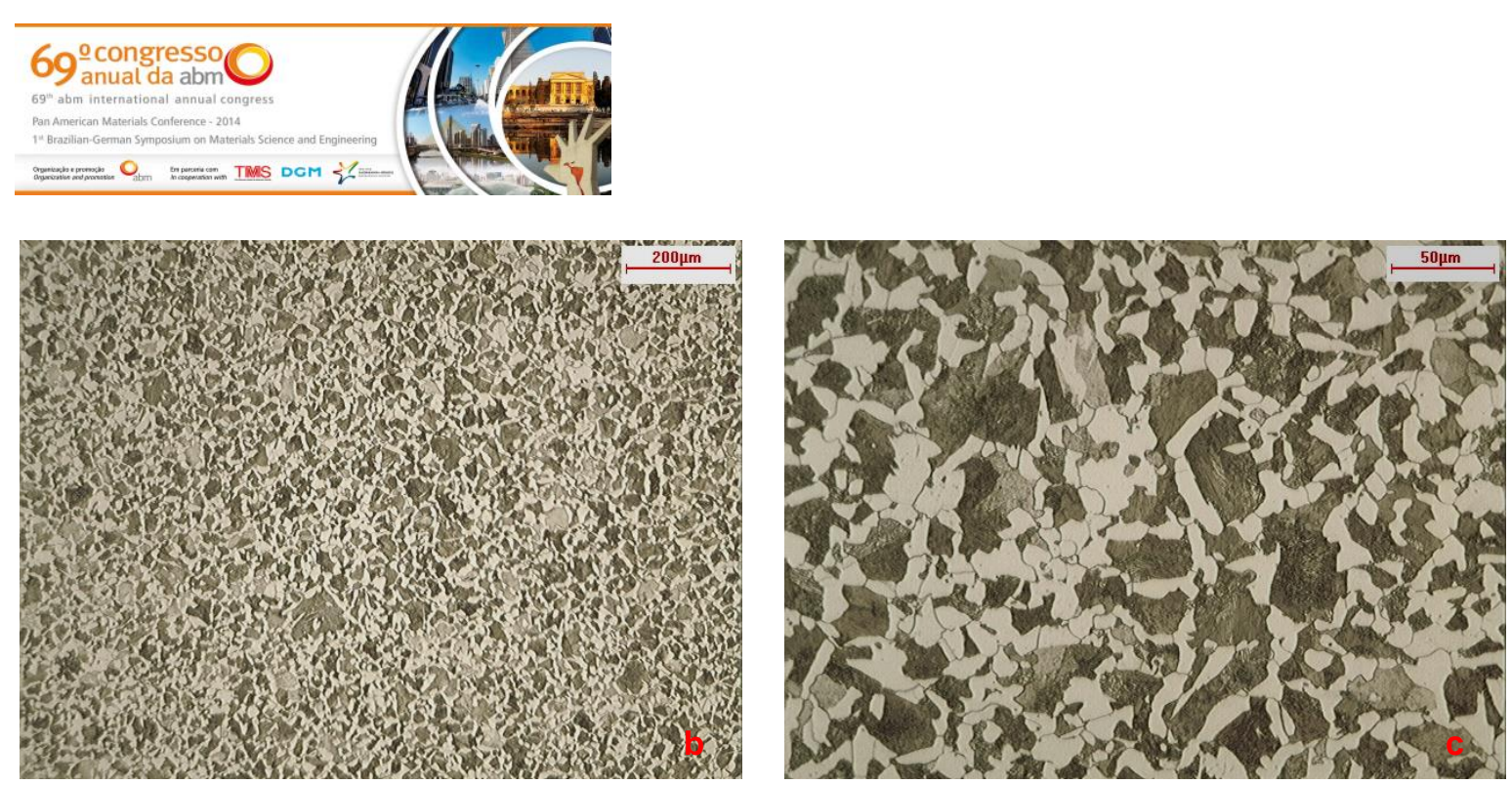

Figura 4. Micrografias do aço ABNT 1045 no estado de entrega. (a) Sem ataque químico - 100x. (b) Nital 2\% - 100x. (c) Nital 2\% - 400x - MO.

\subsection{Influência da Temperatura e Tempo de Austenitização sobre o Tamanho de Grão Austenítico}

A Figura 5 apresenta algumas micrografias (ataque com reativo proposto) obtidas por microscopia óptica das amostras austenitizadas nas temperaturas de $860^{\circ} \mathrm{C}$, $950^{\circ} \mathrm{C}$ e $1100^{\circ} \mathrm{C}$ por diferentes intervalos de tempo (40min, 90min e $180 \mathrm{~min}$ ).

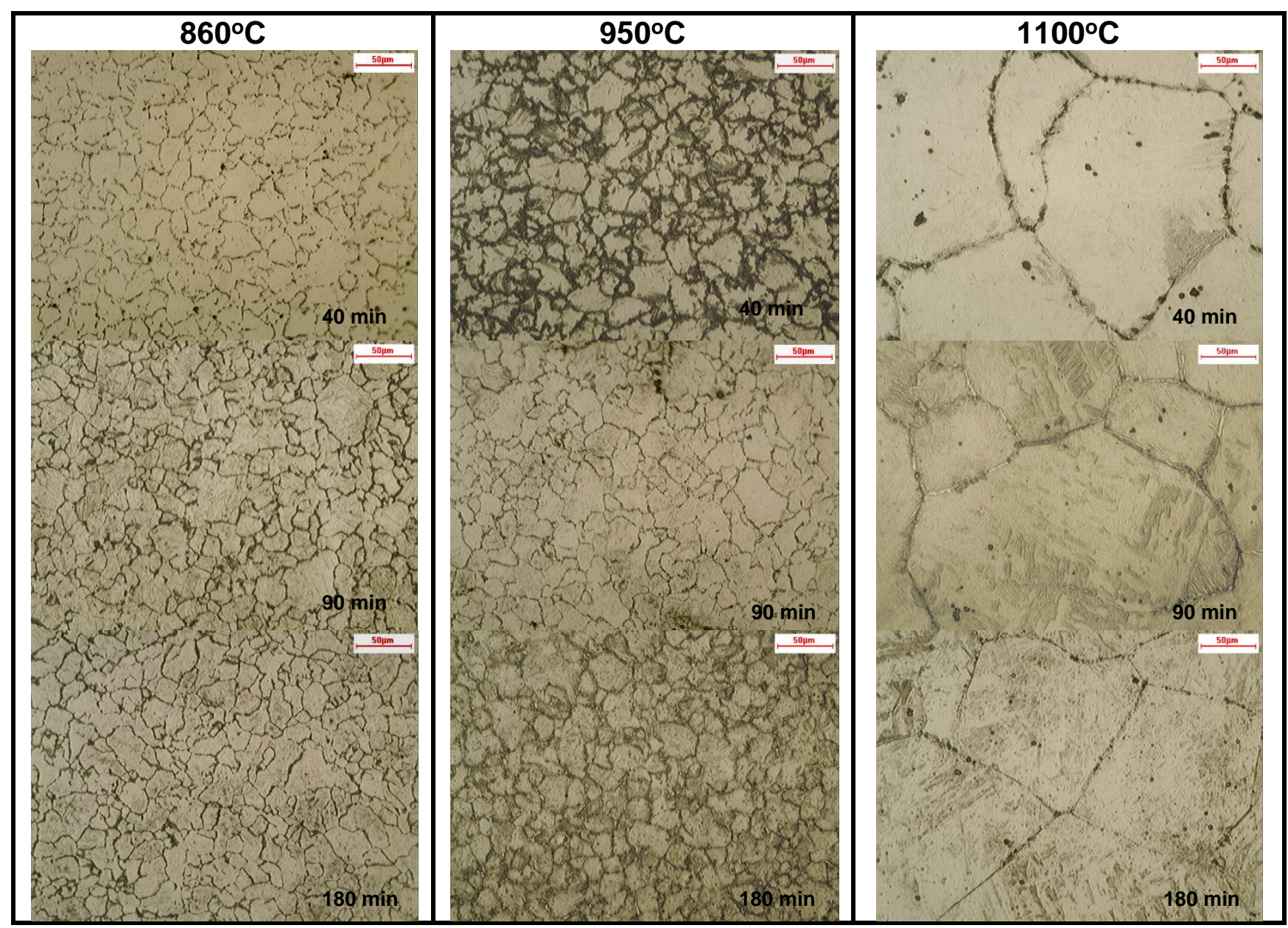

Figura 5. Micrografias do aço ABNT 1045 austenitizado em diferentes temperaturas por diferentes intervalos de tempo - 400x - MO.

* Contribuição técnica ao 69 Congresso Anual da ABM - Internacional e ao 14ํㅡㄹ ENEMET - Encontro Nacional de Estudantes de Engenharia Metalúrgica, de Materiais e de Minas, 21 a 25 de julho de 2014, São Paulo, SP, Brasil. 


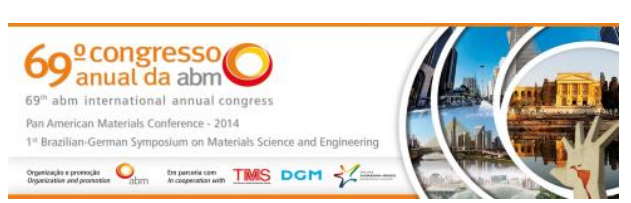

Pode-se observar que o ataque proposto é um eficiente método de contraste para revelar os antigos contornos de grãos austeníticos. Observa-se ainda que o ataque não é homogênio em toda estrutura, variando sua intensidade de região para região da mesma amostra e também de amostra para amostra, mesmo mantendo o tempo de ataque constante.

Por meio da aplicação da metodologia proposta de medição de tamanho de grãos, foi possível avaliar a influência da temperatura e do tempo sobre o tamanho de grão austenítico. A Figura 6 apresenta um comparativo que ilustra o efeito do tempo sobre o tamanho de grão austenítico para cada uma das temperaturas de austenitização, assim como a Figura 7 apresenta o efeito da temperatura fixando-se o tempo de austenitização.

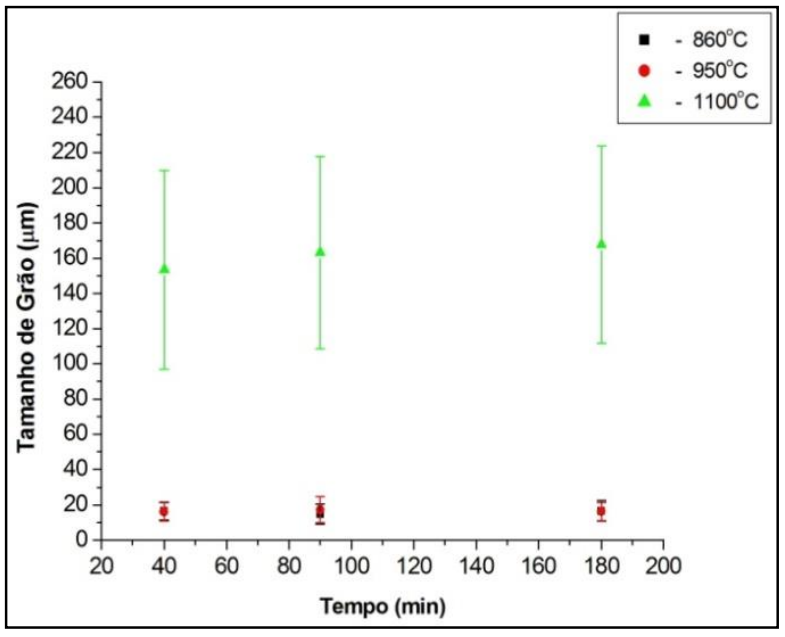

Figura 6. Efeito do tempo de austenitização sobre o tamanho de grão austenítico.

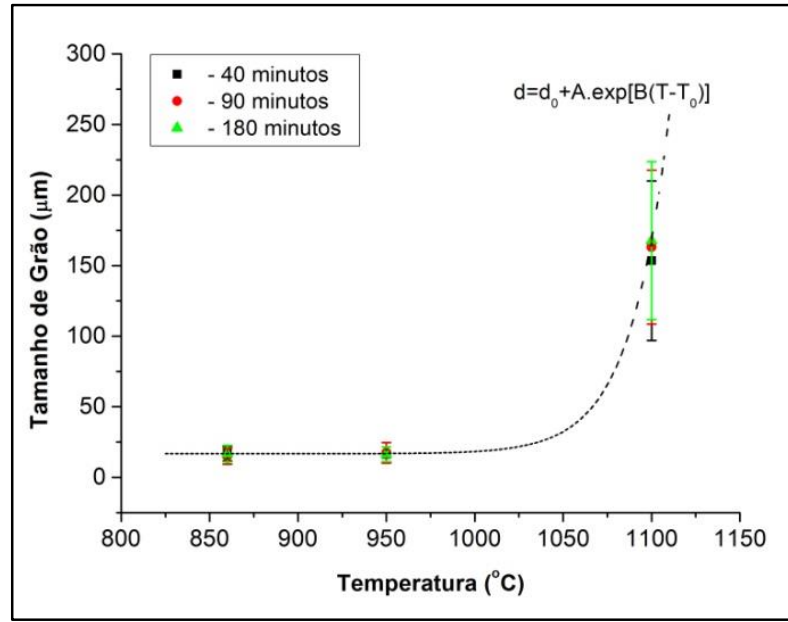

Figura 7. Efeito da temperatura sobre o tamanho de grão austenítico.

Pode-se observar que, para as condições estudadas, o tempo possui pouca influência sobre o tamanho de grão austenítico, ficando claro que quanto menor a temperatura de austenitização menor é a contribuição do tempo no crescimento de grão.

O efeito do tempo de austenitização sobre o tamanho de grão pôde ser aproximado pela equação $d=k \sqrt{t}$. Por meio de regressões não lineares, foi possível determinar $\mathrm{o}$ valor de $\mathrm{k}$ para cada temperatura de tratamento. As amostras tratadas a $860^{\circ} \mathrm{C}$, $950^{\circ} \mathrm{C}$ e $1100^{\circ} \mathrm{C}$ apresentaram valores de $\mathrm{k}$ de $1 \times 10^{-4} \mu \mathrm{m} \cdot \mathrm{s}^{-1 / 2}, 8 \times 10^{-3} \mu \mathrm{m} . \mathrm{s}^{-1 / 2} \mathrm{e}$ $2,2 \mu \mathrm{m} \cdot \mathrm{s}^{-1 / 2}$.

Observa-se que o aumento do tamanho de grão em função da temperatura é exponencial para um mesmo intervalo de tempo de tratamento. Por meio de regressões não lineares, foi possível mostrar que a dependência do tamanho de grão austenítico (d) com a temperatura $(\mathrm{T})$ obedece à lei $d=d_{0}+A \cdot e^{\left[B\left(T-T_{0}\right)\right]}$ onde do é o tamanho de grão austenítico em uma temperatura $T_{0}$, assim como A e t são constantes de ajuste. Para os três intervalos de tempo estudados, considerando $\mathrm{T}_{0}=860^{\circ} \mathrm{C}$, os parâmetros de ajuste encontrados foram: $\mathrm{d}_{0}=16,6 \mu \mathrm{m}, \mathrm{A}=2 \times 10^{-3} \mathrm{e}$ $\mathrm{B}=4,5 \times 10^{-2}{ }^{\circ} \mathrm{C}^{-1}$.

A Figura 8 apresenta um comparativo entre distribuições de frequência de tamanho de grão austenítico para as amostras C, F e I. Pode-se observar um perfil de distribuição normal, de forma que quanto maior a temperatura mais deslocado para a direita ele está. Observa-se que a diferença de distribuição entre as amostras $\mathrm{C}$ e $\mathrm{F}$ é pequena, mas há um significativo deslocamento para a direita das barras

\footnotetext{
* Contribuição técnica ao 69ำ Congresso Anual da ABM - Internacional e ao 14ํㅡㄹ ENEMET - Encontro Nacional de Estudantes de Engenharia Metalúrgica, de Materiais e de Minas, 21 a 25 de julho de 2014, São Paulo, SP, Brasil.
} 


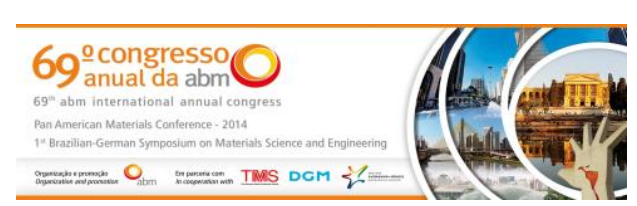

associadas à amostra I. O tamanho médio de grão austenítico encontrado para as amostras C, F e I foram respectivamente $15 \mu \mathrm{m}, 16 \mu \mathrm{m}$ e $169 \mu \mathrm{m}$.

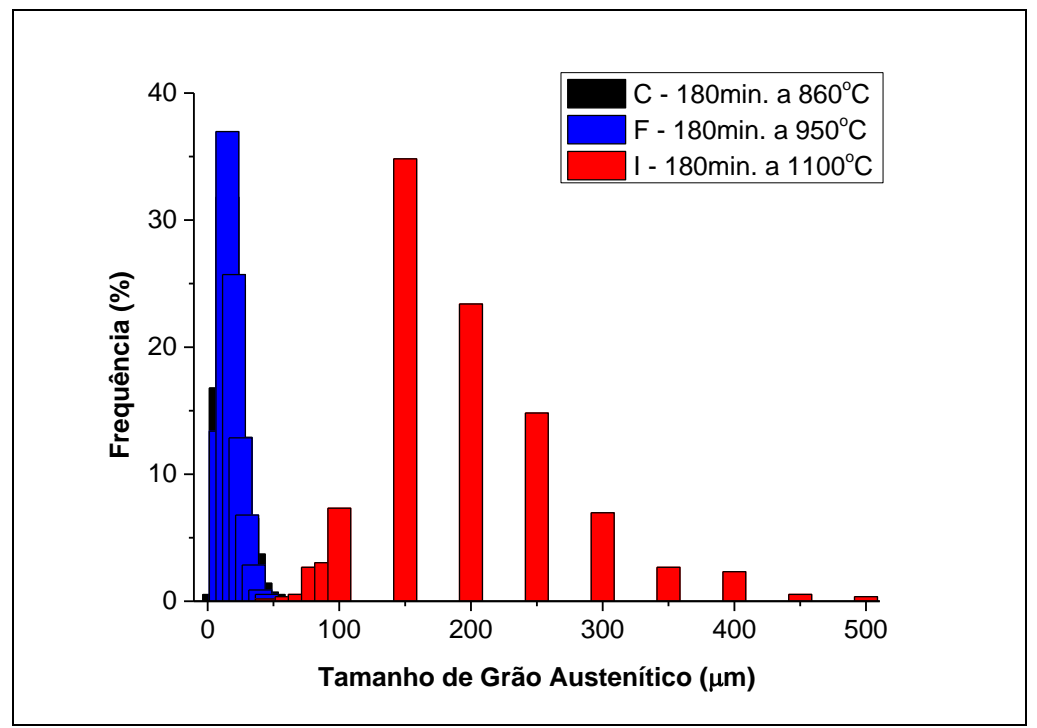

Figura 8. Distribuições de frequência de tamanho de grão austenítico nas amostras C, F e I.

As amostras C, F e I foram novamente preparadas e atacadas com Nital $2 \%$. As mesmas foram analisadas com o auxílio de um microscópio eletrônico de varredura e pôde-se observar que elas apresentam diferenças significativas quanto à morfologia da martensita decorrente da têmpera. As três amostras foram submetidas ao mesmo intervalo de tempo, 180 minutos, porém com diferentes temperaturas de austenitização. Nota-se pela Figura 9 que a partir da amostra $\mathrm{C}$ a martensita é mais grosseira.

A Figura 10 representa os valores médios de durezas HRc encontrados para todas as amostras estudadas. As durezas das amostras tendem a diminuir com o aumento do tamanho de grão austenítico.

A dureza HRc é válida a partir de $20 \mathrm{HRc}$, dessa forma a dureza da amostra do estado de entrega deveria ser realizado em $\mathrm{HRa}$, mas para possibilitar a comparação com as amostras temperadas,fez-se uso da metodologia HRc. O valor de dureza para a amostra do estado de entrega é muito menor, como já era esperado.

\footnotetext{
* Contribuição técnica ao $69^{\circ}$ Congresso Anual da ABM - Internacional e ao 14ํㅡㄹ ENEMET - Encontro Nacional de Estudantes de Engenharia Metalúrgica, de Materiais e de Minas, 21 a 25 de julho de 2014, São Paulo, SP, Brasil.
} 


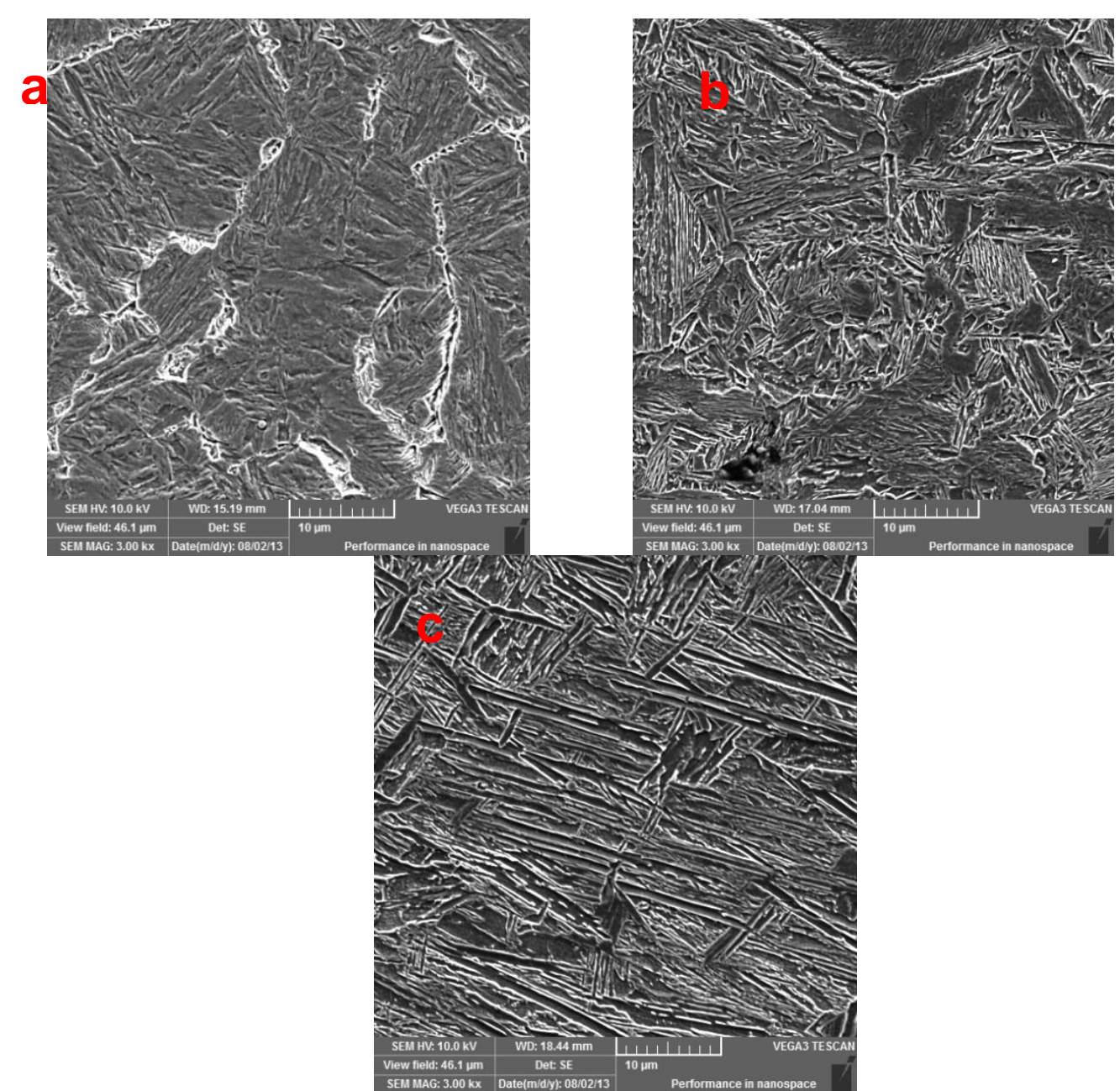

Figura 9. Microestrutura da martensita para as amostras $\mathrm{C}-860^{\circ} \mathrm{C}(\mathrm{a}), \mathrm{F}-950^{\circ} \mathrm{C}$ (b) e I $1100^{\circ} \mathrm{C}(\mathrm{c})$ - MEV - 3000x - nital $2 \%$.

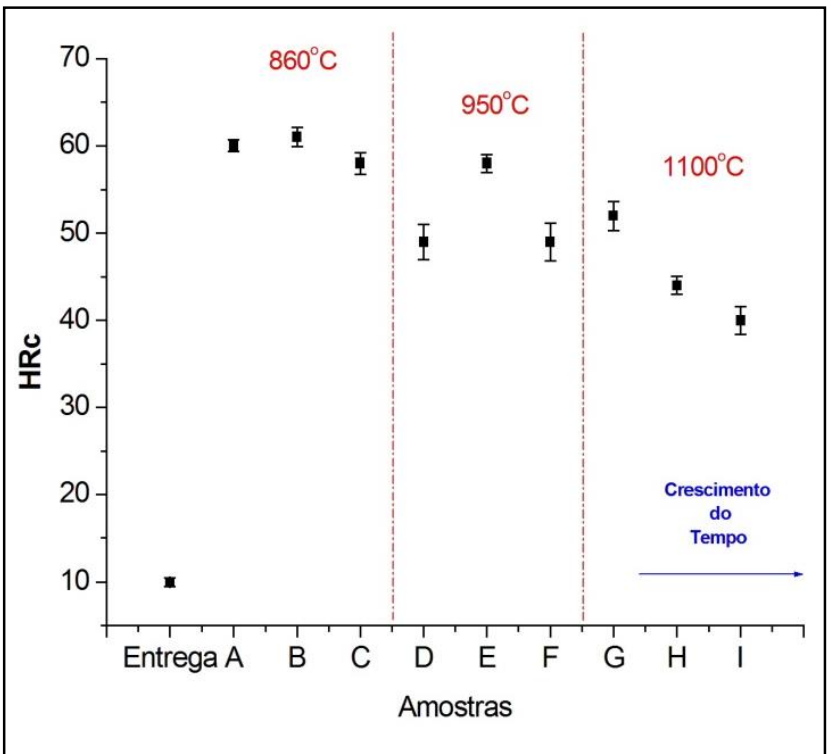

Figura 10. Gráfico da dispersão de durezas das amostras em estudo.

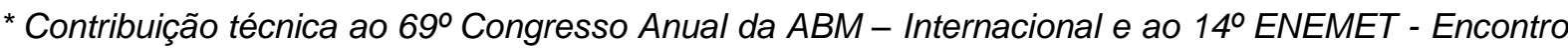
Nacional de Estudantes de Engenharia Metalúrgica, de Materiais e de Minas, 21 a 25 de julho de 2014, São Paulo, SP, Brasil.
} 
12 Andrés GC, Bartolomé CC, Martín DS. Metallographic techniques for the determination of the austenite grain size in medium-carbon microalloyed steels. Materials Characterization. 2001;46:389-398.

13 Lozinskii MG. High temperature metallography. Oxford: UK. Pergamon; 1961.

14 Andrés CG, Caballero FG, Capdevila C, Martin DS. Revealing austenite grain boundaries by thermal etching: advantages and disadvantages. Materials Characterization. 2003;49:121-127.

15 Cho KS, Sim HS, Kim JH, Choi JH, Lee KB, Yang HR, et al. A novel etchant for revealing the prior austenite grain boundaries and matrix information in high alloy steels. Materials Characterization. 2008;59:786-793. 